\title{
Consumption of Shed Slkin and Scavenging Behavior by Common Indian Trinket Snakes, Coelognathus helena helena (Daudin 1803)
}

\author{
Rahul V. Deshmukh ${ }^{1}$, Sagar A. Deshmukh², Swapnil A. Badhekar ${ }^{3}$, Prajwal S. Raut ${ }^{4}$, and Shubham D. Katgube \\ ${ }^{1}$ H. No. 26, Teacher colony, Brahmani - Kalmeshwar, Nagpur, M.S. - 441501 (rahul30.snake@gmail.com) \\ ${ }^{2}$ Behind Potdar Nursing Home, Kalmeshwar, Nagpur, M.S. - 441501 (sd.snakefriend@gmail.com) \\ ${ }^{3}$ Tiwaskarwadi, Raipur, Hingana, Nagpur, M. S. - 441110 (swapnilbadhekar86@gmail.com) \\ ${ }^{4}$ Bank of India Road, Kalmeshwar, Nagpur, M.S. - 441501 (prajvalraut1234@gmail.com) \\ ${ }_{5}^{5}$ Saoner Road, Kalmeshwar, Nagpur, M.S. - 441501 (shubham95.snake@gmail.com)
}

$\mathrm{T}^{\mathrm{b}}$ he Common Indian Trinket Snake (Coelognathus helena helena) is one of the most frequently encountered snakes in India. The species is widely distributed throughout India and also occurs in Nepal, Bangladesh, and Sri Lanka (Whitaker and Captain 2004). Typical prey consists of small mammals, lizards, snakes, and frogs (Whitaker and Captain 2004). Herein we report consumption of a shed snake skin and an instance of scavenging behavior.

At 2025 h on 15 July 2018, we rescued an adult Common Indian Trinket Snake near Tel Ghani, Kalmeshwar, Nagpur, Maharashtra, India $\left(21^{\circ} 14,08 » N\right.$, $\left.78^{\circ} 54,34.7 » E\right)$. During the rescue, we noticed that the snake was ingesting a recently shed molt of an unidentified snake (Fig. 1). The snake took about
6 min to ingest the skin. We released the snake into appropriate habitat in the outskirts of the city.

At 2255 h on 5 August 2018, during a survey along the Kalmeshwar-to-Saoner road near the Chandrabhaga River, Maharashtra, India $\left(21^{\circ} 28^{\prime} 69.42^{\prime \prime} \mathrm{N}, 78^{\circ} 91^{\prime} 44.51^{\prime \prime} \mathrm{E}\right)$, we encountered a road-killed Common Indian Trinket Snake (total length $960.25 \mathrm{~mm}$; Fig. 2) with a piece of chicken (approximately $50.8 \mathrm{~mm}$ in diameter), such as that used in chicken biryani, in its mouth. A plastic bag containing scraps of biryani, plastic plates, boiled rice, and paper was nearby. The improper disposal of food waste on or along roads might attract mammals, birds, and, in this instance, a snake, exposing them to vehicular mortality.
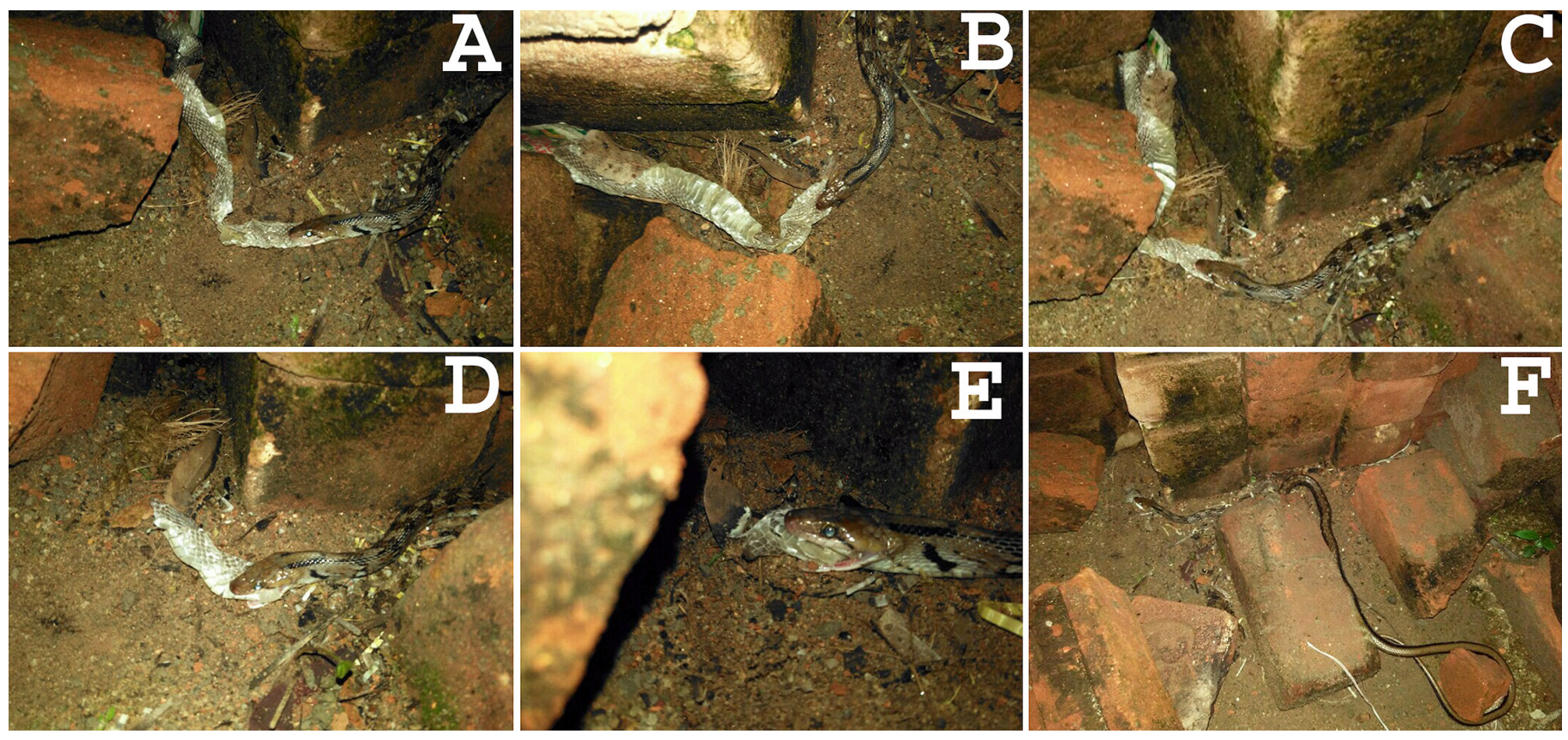

Fig. 1. An adult Common Indian Trinket Snake (Coelognathus helena helena) ingesting a recently shed molt of an unidentified snake. Photographs by Rahul V. Deshmukh.

Copyright (C) 2018. Rahul V. Deshmukh. All rights reserved. 

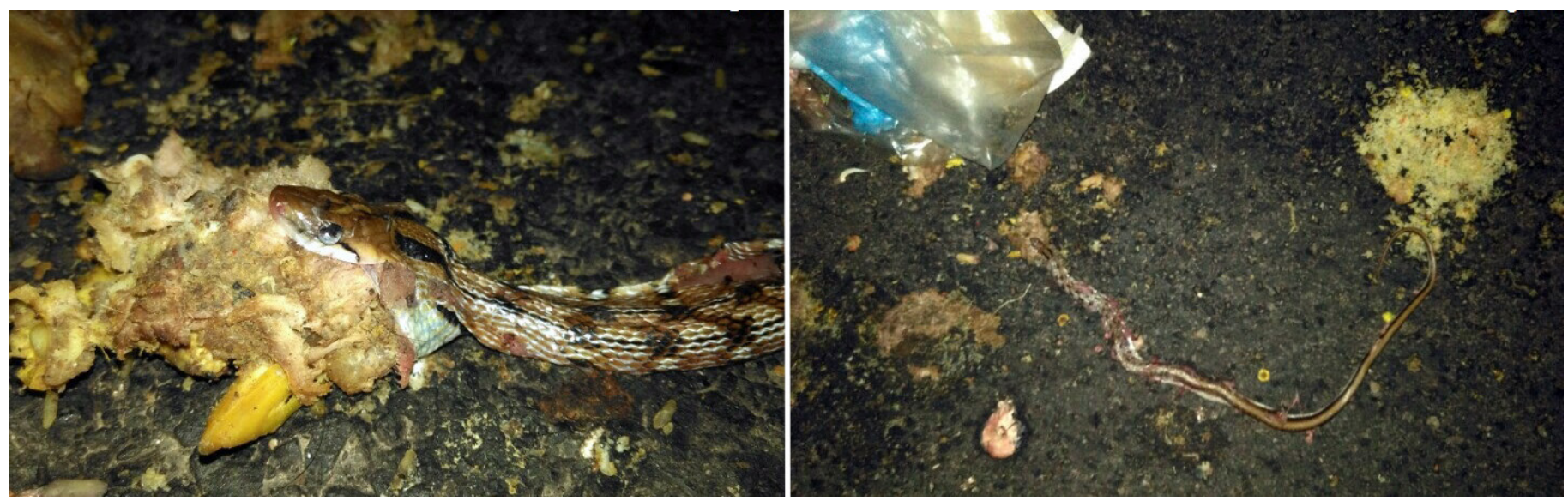

Fig. 2. A road-killed Common Indian Trinket Snake (Coelognathus helena helena) with a discarded piece of chicken in its mouth. The plastic bag visible in the second image contained pieces of chicken biryani, plastic plates, boiled rice, and paper. Photographs by Rahul V. Deshmukh.

Ayres (2012), who reported scavenging by snakes in the genus Natrix, suggested that such behavior in snakes might be more common than previously thought, often overlooked, or simply not observed. Lillywhite et al. $(2002,2008)$ recorded scavenging by Florida Cottonmouths (Agkistrodon conanti) at island bird rookeries and in an intertidal zone, respectively. Shivik and Clark (2012) noted that snakes, such as the Brown Treesnake (Boiga irregularis), that use chemical cues to find food appear to scavenge more frequently than those relying on visual or thermal cues. Sharma et al. (2016) reported the consumption of inanimate objects by an Oriental Ratsnake (Ptyas mucosa) using chemical cues. Mohopatra (2011) and Deshmukh et al. (2016) reported scavenging behavior in Common Indian Kraits (Bungarus caeruleus), and Deshmukh et al. (2017) documented consumption of a plastic bag that had contained food by another Common Indian Krait.

\section{Acknowledgements}

We thank Dr. Pratyush Mohopatra, ZSI, Jabalpur, Rahul Khot, Bombay Natural History Society, Mumbai, Dr. B.V. Jadhav, Swapnil Bhondawe, Sarang Hadke, Sushil Pillewan, Ajit Deshmukh, Majesh Thawakar, Ankush Kukde, Gaurav Bhujade, Atul Bhelkar, Lalit Nehare, Tushar Thakur, and Akshay Puri for encouragement, support, and assistance in the field.

\section{Literature Cited}

Ayres, C. 2012. Scavenging in the genus Natrix. Acta Herpetologica 7: 171-174.

Deshmukh, R.V., S.A, Deshmukh, and S.A. Badekar. 2015. Rescued records of snakes from Nagpur District, Maharashtra with data on unrecorded species. Reptile Rap 17: 34-43.

Deshmukh, R.V., S.A. Deshmukh, and S.A. Badhekar. 2016. A second record of scavenging behavior in Common Indian Krait (Bungarus caeruleus [Schneider 1801]) from India. Reptiles \& Amphibians 23: 169-170.

Deshmukh, R.V., S.A. Deshmukh, and S.A. Badhekar. 2017. A plastic bag consumed by a Common Indian Krait, Bungarus caeruleus (Schneider 1801). Reptiles \& Amphibians 24: 172-174.

Lillywhite, B.H., C.M. Sheehy III, and M.D. McCue 2002. Scavenging behaviors of Cottonmouth snakes at island bird rookeries. Herpetological Review 33: 259-261.

Lillywhite, B.H., C.M. Sheehy, III, and F. Zaidan, III. 2008. Pitviper scavenging at the intertidal zone: An evolutionary scenario for invasion of the sea. BioScience 58: 947-955.

Monopatra, P.P. 2011. Bungarus caeruleus (Common Krait). Scavenging. Herpetological Review 42: 436-437.

Sharma, V., A. Sayyad, and R. Bhandari. 2016. Herbivory and inanimate objects in the diet of the Oriental Ratsnake, Ptyas mucosa (Linnaeus 1758) Reptiles \& Amphibians 23: 102-103.

Shivik, J.A., and L. Clark. 1997. Carrion seeking in Brown Tree Snakes: Importance of olfactory and visual cues. Journal of Experimental Zoology 279: 549-553.

Smith, M.A. 1943. The Fauna of British India, Ceylon and Burma, Including the Whole of the Indo-Chinese Sub-Region. Reptilia and Amphibia. Volume IIISerpentes. Taylor and Francis, London, UK.

Whitaker, R. and A. Captain. 2004. Snakes of India. The Field Guide. Draco Books, Chennai, India. 